\title{
Interactions of laminin with the amyloid B peptide. Implications for Alzheimer's disease
}

C. Morgan and

N.C. Inestrosa
Centro de Regulación Celular y Patología, Departamento de

Biología Celular y Molecular, Facultad de Ciencias Biológicas,

Pontificia U niversidad Católica de Chile, Santiago, Chile

\section{Correspondence \\ N.C. Inestrosa \\ Centro de Regulación Celular \\ y Patología \\ Departamento de Biología Celular \\ y Molecular, FCB, PU C \\ Alameda, 340 \\ Casilla 114-D \\ Santiago \\ Chile \\ Fax: + 56-2-686-2717 \\ E-mail: ninestr@genes.bio.puc.cl \\ Presented at \\ SIMEC 2000 - International \\ Symposium on Extracellular \\ Matrix, Angra dos Reis, RJ, \\ Brazil, September 24-27, 2000. \\ Research supported by a Presidentia Chair in Science (1999-2001) and a FO NDAP grant in Biomedicine (No. 13980001 ) to N.C. Inestrosa and FONDECYT (Nos. 2970070 and 4000011 ) to C. Morgan.}

Received October 19, 2000 Accepted February 5, 2001

\section{Abstract}

Extensive neuronal cell loss is observed in Alzheimer's disease. Laminin immunoreactivity colocalizes with senile plaques, the characteristic extracellular histopathological lesions of Alzheimer brain, which consist of the amyloid $B(A B)$ peptide polymerized into amyloid fibrils. These lesions have neurotoxic effects and have been proposed to be a main cause of neurodegeneration. In order to understand the pathological significance of the interaction between laminin and amyloid, we investigated the effect of laminin on amyloid structure and toxicity. We found that laminin interacts with the Aß1-40 peptide, blocking fibril formation and even inducing depolymerization of preformed fibrils. Protofilaments known to be intermediate species of $A ß$ fibril formation were also detected as intermediate species of laminin-induced $A ß$ fibril depolymerization. Moreover, laminin-amyloid interactions inhibited the toxic effects on rat primary hippocampal neurons. As a whole, our results indicate a putative anti-amyloidogenic role of laminin which may be of biological and therapeutic interest for controlling amyloidosis, such as those observed in cerebral angiopathy and Alzheimer's disease.

\section{Introduction}

Laminin is a major basement membrane glycoprotein $\left(\mathrm{M}_{\mathrm{r}} \sim 850 \mathrm{kDa}\right)$ widely distributed in the extracellular matrix (ECM). At least 11 isoforms of laminin have been described due to the presence of five different $\alpha$ chains $(\alpha 1-\alpha 5)$ of $200-400 \mathrm{kDa}$ which combine with $\beta(220 \mathrm{kDa})$ and $\gamma(210 \mathrm{kDa})$ chains into disulfide-bonded heterotrimers arranged in a cross-shaped structure $(1,2)$. These three chains are coded by different genes (3-5). The C-terminal globular domains of the $\alpha$ chain are critical for appropriate assembly of the whole glycoprotein (6). This region is also important for driving laminin polymerization and heparin binding
Key words

- Extracellular matrix

- Laminin

- Amyloid ß peptide

- Neuronal injury

- Neurodegenerative disease
$(7,8)$. Several other ECM proteins may bind laminin through these globular domains, such as perlecan, $\alpha$-dystroglycan, fibulin- 1 , fibulin-2, and nidogen-2 $(9,10)$. Because of its large size, complexity and multidomain nature, laminin exhibits a variety of functions still not completely understood, namely the ability of laminin to keep the ECM assembled, to promote neurite outgrowth, growth cone guidance, pathfinding, and synapse formation $(11,12)$.

\section{The importance of amyloid B peptide in Alzheimer's disease}

Alzheimer's disease (AD) is a progressive neurodegenerative disease characterized 
by a loss of memory which finally determines the clinical onset of dementia. Alzheimer brains are histopathologically characterized by numerous senile plaques and neurofibrillary tangles. Both lesions are considered to be of pivotal importance to understand AD. In addition, genetic evidence points at the regulation of amyloid precursor protein (APP) metabolism as a key factor in the pathogenesis of AD (13). Amyloid-derived neurotoxicity is widely considered as a main factor explaining the neurodegenerative changes observed in AD. The neurotoxic effect of amyloid $B(A B)$ peptide, a proteolytic fragment of APP, is associated with its polymerization state as amyloid fibrils $(14,15)$. Studies of amyloid-derived neurotoxicity in vivo have shown an increased vulnerability to neurotoxicity with aging (16), suggesting the participation of some age-dependent factors.

\section{ECM components and APP}

Because of the extracellular deposition of $A B$ peptide in senile plaques, particular attention has been paid to interactions between amyloid and ECM components (17). Indeed, several basement membrane com- ponents such as heparan sulfate proteoglycans, type IV collagen and laminin have been found in senile plaques (18). Moreover, proteoglycans and laminin interact with APP (19-21) and these interactions seem to disrupt the normal associations among ECM components (22), suggesting that an overproduction of APP may change the normal functions of ECM. On the other hand, APP metabolism is affected by ECM components both in microglial (23) and neuronal (24) cell types.

\section{The anti-amyloidogenic role of laminin}

Laminin immunoreactivity is observed mainly associated with blood vessels and reactive astrocytes in normal brains but also in neuronal cell bodies in most parts of the developing and adult rat central nervous system (25). Its expression seems to be increased after brain injury (26) and in the brain of $\mathrm{AD}$ and Down syndrome patients (27). In order to examine the pathological significance of laminin induction in Alzheimer brains, we studied the effect of laminin on $A B$ peptide polymerization, and we showed for the first time that laminin was a
A

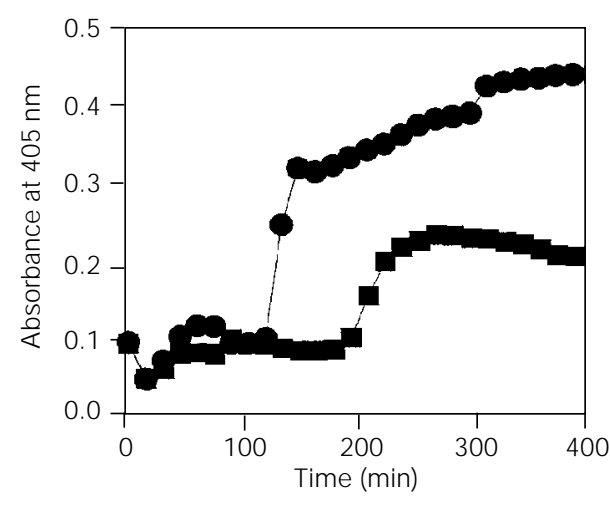

B

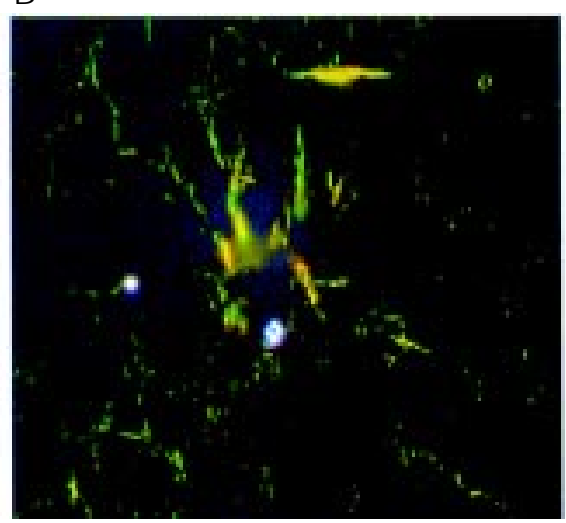

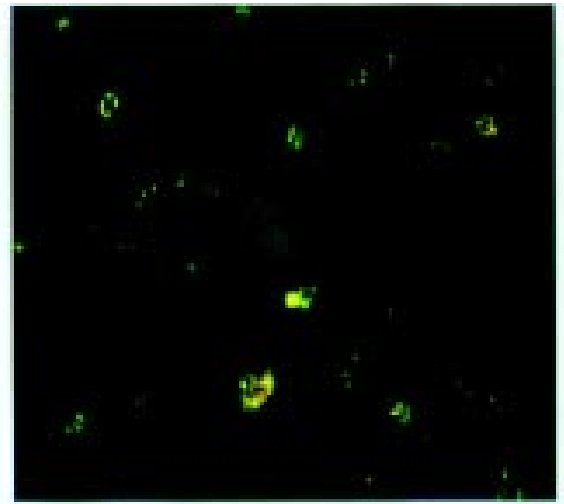

Figure 1. Inhibition of amyloid ß $(A ß)$ peptide polymerization by laminin. A, Aß1-40 (100 $\mu \mathrm{M})$ peptide polymerization assay carried out in the presence (squares) or absence (circles) of $100 \mathrm{nM}$ mouse laminin-1 (with stirring at room temperature in PBS, pH 7.4). Turbidity measurements were undertaken at the indicated time points. B, The final products of the assay were examined by polarized light microscopy after Congo red staining. Abundant green birefringent material was observed in the absence of laminin (left), indicating the presence of amyloid; conversely, a scarce positive reaction was observed in the presence of laminin (right). 
potent inhibitor of $A B$ fibril formation $(28,29)$. Figure $1 \mathrm{~A}$ shows a turbidity assay indicating that $A B$ aggregation in the presence of laminin was clearly decreased, and that the formation of amyloid was also diminished in the presence of laminin, as evidenced by Congo red staining (Figure 1B). These observations confirm those obtained by other authors $(30,31)$. Since an inhibition of fibril formation is expected to be accompanied by an attenuation of amyloid neurotoxicity, we have proposed that laminin may have a therapeutic potential in the treatment of AD. In fact, a diminished neurotoxicity of amyloid has been observed in the presence of laminin in rat primary hippocampal neurons (Figure 2). Similar results have been observed in primary cortical cells (32).

Since a kinetic inhibition of amyloidogenesis may retard but not reverse $A \beta$ fibril formation, we decided to investigate the ability of laminin to depolymerize preformed $A B$ fibrils (33). The studies were carried out using molar ratios of $A B$ to laminin- 1 of 2,500 or less. Amyloid depolymerization induced by laminin is a concentration- and time-dependent reaction (Figure 3A) characterized by the appearance of protofilaments at the expenses of preformed fibrils, which finally leads to their clearance, forming amorphous non-amyloid material, as observed by electron microscopy examination (Figure 3B). These observations suggest that laminin behaves as a thermodynamic inhibitor of amyloidogenesis. But if so, why does amyloidosis proceed in Alzheimer brains? Several answers are possible, including one that may involve laminin degradation. In fact, it has been shown that plasmin-catalyzed degradation of laminin mediates neuronal death in the hippocampus after excitotoxic injury with kainate (34). In that study, the authors demonstrated that disruption of laminin-neuron interaction makes neurons sensitive to excitotoxic death. Therefore, it is reasonable to assume that the interaction of laminin with the $A ß$ peptide may disrupt normal interactions with cells. Moreover, we have recently found that several laminin-derived peptides, including the IKVAV sequence (neurite promotor activity; 21), inhibit amyloidogenesis. The efficacy of laminin in depolymerizing A 3 suggests that this glyco-
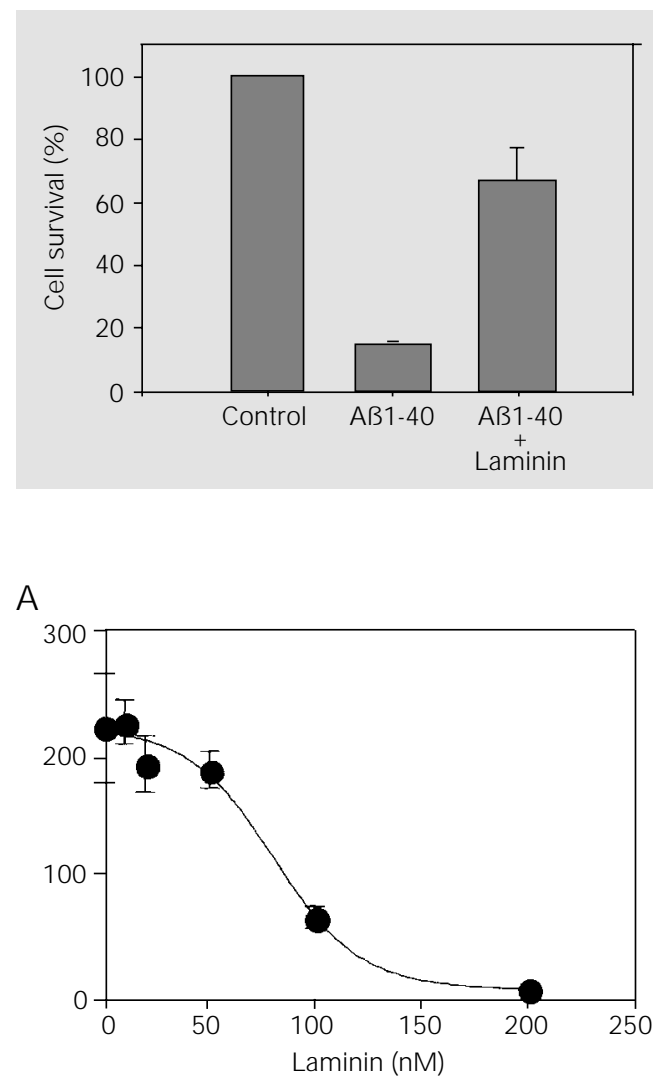

B

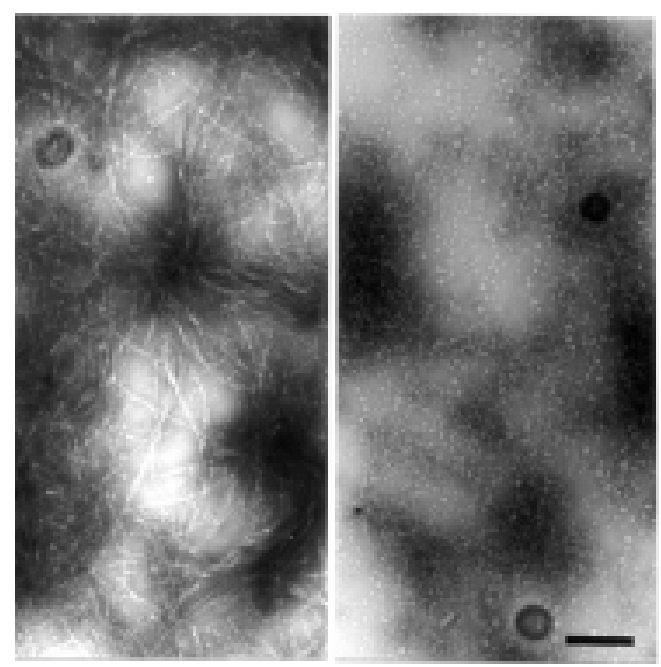

Figure 2. Inhibition of amyloid B (Aß) fibril neurotoxicity by laminin. Rat hippocampal neurons in culture were incubated for $24 \mathrm{~h}$ with $10 \mu \mathrm{M} A ß$ fibrils formed in the absence (Aß1$40)$ or presence of laminin (Aß1-40 + laminin) as indicated in the legend of Figure 1. Control cells (Control) were incubated with an equivalent volume of PBS, pH 7.4. Cell survival was determined by monitoring $\mathrm{MTT}$ reduction (32) and is reported as percentage of the control assay.

Figure 3. Depolymerization of amyloid $B$ (Aß) fibrils by laminin. Aß1-40 $(250 \mu \mathrm{M})$ fibrils were incubated with mouse laminin- 1 at the indicated concentrations for $4 \mathrm{~h}$ at room temperature $(20 \mathrm{mM}$ sodium phosphate buffer, $150 \mathrm{mM}$ $\mathrm{NaCl}, \mathrm{pH}$ 7.2). A, The presence of amyloid fibrils was assessed by thioflavine-T fluorescence as expressed in arbitrary units. $B$, Transmission electron micrographs of $A ß$ fibrils used as starting material (left); amyloid fibrils were depolymerized to protofilaments in the presence of $100 \mathrm{nM}$ laminin (right). These protofilaments were completely cleared in the presence of $200 \mathrm{nM}$ laminin (data not shown). Bar $=0.25 \mu \mathrm{m}$. 
protein may exhibit a number of active sequences interacting with amyloid. This may involve the loss of several normal functions of laminin including its role in the survival of neurons.

\section{Therapeutic potential of laminin in Alzheimer's disease}

The anti-amyloidogenic properties of laminin make it suitable for therapeutic use; however, several points have to be considered. First, the interactions between laminin and amyloid may disrupt normal functions of laminin including its role in neuronal survival. Therefore, it is important to determine which laminin regions are involved in this anti-amyloidogenic activity in order to synthesize defined laminin-derived peptides or peptidomimetics. Second, such peptides have to cross the blood-brain barrier and find their appropriate target regions in the brain. This problem may not be difficult to solve considering that pentapeptides disrupting the amyloid fibril structure and satisfying this property have already been designed (35).

\section{References}

1. Timpl R (1996). Macromolecular organization of basement membranes. Current Opinion in Cell Biology, 8: 618-624.

2. Beck K, Hunter I \& Engel J (1990). Structure and function of laminin: anatomy of a multidomain glycoprotein. FASEB J ournal, 4: 148-160.

3. Barlow D, Green $M$, Kurkinen $M$ \& Hogan B (1984). Sequencing of laminin B chain CDNAs reveals $C$-terminal regions of coiled-coil $\alpha$-helix. EMBO J ournal, 3 : 2355-2362.

4. Sasaki M \& Yamada Y (1987). The laminin B2 chain has a multidomain structure homologous to the B1 chain. J ournal of Biological Chemistry, 262: 17111-17117.

5. Sasaki M, Kleinman HK, Huber H, Deutzmann R \& Yamada Y (1988). Laminin, a multidomain protein. The $A$ chain has a unique globular domain and homology with the basement membrane proteoglycan and the laminin B chains. J ournal of Biological Chemistry, 263: 16536-16544.

6. Utani A, Nomizu M, Timpl R, Roller PD \& Yamada $Y$ (1994). Laminin chain assembly. Specific sequences at the $C$ terminus of the long arm are required for the formation of specific double- and triplestranded coiled-coil structures. J ournal of Biological Chemistry, 269: 19167-19175.

7. Yurchenco PD, Tsilibary EC, Charonis AS \& Furthmayr H (1985). Laminin polymerization in vitro. Evidence for a two-step assembly with domain specificity. J ournal of Biological Chemistry, 260: 7636-7644.

8. Yurchenco PD, Cheng Y-S \& Schittny J C (1990). Heparin modulation of laminin polymerization. J ournal of Biological Chem- istry, 265: 3981-3991.

9. Talts J F, Andac Z, Göhring W, Brancaccio A \& Timpl R (1999). Binding of the $G$ domains of laminin $\alpha 1$ and $\alpha 2$ chains and perlecan to heparin, sulfatides, $\alpha$-dystroglycan and several extracellular matrix proteins. EMBO J ournal, 18: 863-870.

10. Andac Z, Sasaki T, Mann K, Brancaccio A, Deutzmann R \& Timpl R (1999). Analysis of heparin, $\alpha$-dystroglycan and sulfatide binding to the $\mathrm{G}$ domain of the laminin $\alpha 1$ chain by site-directed mutagenesis. J ournal of Molecular Biology, 287: 253-264.

11. Venstrom KA \& Reichardt LF (1993). Extracellular matrix. 2: Role of extracellular matrix molecules and their receptors in the nervous system. FASEB J ournal, 7: 996-1003.

12. Luckenbill-Edds L (1997). Laminin and the mechanism of neuronal outgrowth. Brain Research Reviews, 23: 1-27.

13. Selkoe DJ (1999). Translating cell biology into therapeutic advances in Alzheimer's disease. Nature, 399: A23-A31.

14. Pike CJ, Burdick D, Walencewicz AJ, Glabe CG \& Cotman CW (1993). Neurodegeneration induced by ß-amyloid peptides in vitro: the role of peptide assembly state. J ournal of Neuroscience, 13: 16761687.

15. Lorenzo A \& Yankner B (1994). ß-Amyloid neurotoxicity requires fibril formation and is inhibited by congo red. Proceedings of the National Academy of Sciences, USA, 91: 12243-12247.

16. Geula C, Wu CK, Saroff D, Lorenzo A, Yuan M \& Yankner BA (1998). Aging renders the brain vulnerable to amyloid $\beta$ - protein neurotoxicity. Nature Medicine, 4 : 827-831.

17. Brandan E \& Inestrosa NC (1993). Extracellular matrix components and amyloid in neuritic plaques of Alzheimer's disease. General Pharmacology, 24: 1063-1068.

18. Perlmutter LS, Barrón E, Saperia D \& Chui HC (1991). Association between vascular basement membrane components and the lesions of Alzheimer's disease. J ournal of Neuroscience Research, 30: 673681.

19. Cáceres J \& Brandan E (1997). Interaction between Alzheimer's disease BA4 precursor protein (APP) and the extracellular matrix: evidence for the participation of heparan sulfate proteoglycans. J oumal of Cellular Biochemistry, 65: 145-158.

20. Narindrasorasak $S$, Lowery $D E$, Altman RA, Gonzalez-DeWhitt PA, Greenberg BD $\&$ Kisilevsky R (1992). Characterization of high affinity binding between laminin and Alzheimer's disease amyloid precursor proteins. Laboratory Investigation, 67: 643-652.

21. Kibbey MC, J ucker M, Weeks BS, Neve RL, Van Nostrand WE \& Kleinman HK (1993). B-Amyloid precursor protein binds to the neurite-promoting IKVAV site of laminin. Proceedings of the National Academy of Sciences, USA, 90: 10150-10153.

22. Narindrasorasak $S$, Altman RA, GonzalezDeWhitt P, Greenberg BD \& Kisilevsky R (1995). An interaction between basement membrane and Alzheimer amyloid precursor proteins suggests a role in the pathogenesis of Alzheimer's disease. Laboratory Investigation, 72: 272-282. 
23. Möning $U$, Sandbrink R, Weidemann A, Banati RB, Masters CL \& Beyreuther K (1995). Extracellular matrix influences the biogenesis of amyloid precursor protein in microglial cells. J ournal of Biological Chemistry, 270: 7104-7110.

24. Bronfman FC, Soto C, Tapia L, Tapia V \& Inestrosa NC (1996). Extracellular matrix regulates the amount of the $ß$-amyloid precursor protein and its amyloidogenic fragments. J ournal of Cellular Physiology, 166: 360-369.

25. Hagg T, Muir D, Engvall E, Varon $S \&$ Manthorpe M (1989). Laminin-like antigen in rat CNS neurons: distribution and changes upon brain injury and nerve growth factor treatment. Neuron, 3: 721732.

26. Liesi P, Kaakkola S, Dahl D \& Vaheri A (1984). Laminin is induced in astrocytes of adult brain by injury. EMBO J ournal, 3 : 683-686.
27. Murtomäki S, Risteli J, Risteli L, Koivisto U-M, J ohansson S \& Liesi P (1992). Laminin and its neurite outgrowth-promoting domain in the brain in Alzheimer's disease and Down syndrome patients. J ournal of Neuroscience Research, 32: 261273.

28. Bronfman FC, Garrido J , Alvarez A, Morgan C \& Inestrosa NC (1996). Laminin inhibits amyloid-ß-peptide fibrillation. Neuroscience Letters, 218: 201-203.

29. Bronfman FC, Alvarez A, Morgan C \& Inestrosa NC (1998). Laminin blocks the assembly of wild-type $A ß$ and the Dutch variant peptide into Alzheimer's fibrils. Amyloid, 5: 16-23.

30. Monji A, Tashiro K, Yoshida I, Hayashi Y \& Tashiro N (1998). Laminin inhibits Aß40 fibril formation promoted by apolipoprotein E4 in vitro. Brain Research, 796: 171175.

31. Monji A, Tashiro K, Yoshida I, Hayashi Y \&
Tashiro N (1998). Laminin inhibits Aß42 fibril formation in vitro. Brain Research, 788: 187-190.

32. Drouet B, Pinçon-Raymond M, Chambaz J \& Pillot T (1999). Laminin 1 attenuates ß-amyloid peptide $A ß(1-40)$ neurotoxicity of cultured fetal rat cortical neurons. J ournal of Neurochemistry, 73: 742-749.

33. Morgan C \& Garrido J (1998). Laminin disaggregates amyloid B-fibrils. Neurobiology of Aging, 19: S45 (Abstract 185).

34. Chen Z-L \& Strickland S (1997). Neuronal death in the hippocampus is promoted by plasmin-catalyzed degradation of laminin. Cell, 91: 917-925.

35. Soto C, Kindy MS, Baumann M \& Frangione B (1996). Inhibition of Alzheimer's amyloidosis by peptides that prevent $B$ sheet conformation. Biochemical and Biophysical Research Communications, 226: 672-680. 